\title{
Notas sobre as políticas de desenvolvimento regional segundo as Constituições Federais do Brasil e o papel dos Fundos Constitucionais de Financiamento pós-1988
}

Fernando Cezar de Macedo Instituto de Economia da Universidade Estadual de Campinas (Unicamp)

\begin{abstract}
Resumo
Este trabalho discute o papel dos Fundos Constitucionais de Financiamento para a dinâmica regional brasileira. Parte de uma perspectiva teórica e histórica da problemática regional do país, interpretando-a como resultado dos conflitos que emergem desde seu passado colonial e de seu padrão de acumulação. Ambos definem o papel do país na divisão internacional do trabalho e sua organização socioespacial. Observa-se que o controle ferrenho do território, a superexploração da força de trabalho e os fundos públicos representam vetores determinantes na maneira como as regiões brasileiras são articuladas à lógica de acumulação capitalista. $\mathrm{O}$ artigo encontra-se dividido em cinco partes. Na primeira, faz-se uma apresentação do trabalho. $\mathrm{Na}$ segunda, faz-se uma breve consideração da problemática regional brasileira. $\mathrm{Na}$ terceira, discute-se como a questão regional no Brasil é tratada nas Constituições Federais. Na quarta, é feita uma análise dos Fundos Constitucionais de Financiamento. $\mathrm{Na}$ quinta, aparecem as conclusões.
\end{abstract}

Palavras-chave | Brasil; desenvolvimento regional; Fundos Constitucionais de Financiamento.

Código JEL | O18; R12; R58.

\section{NOTES ON THE REGIONAL DEVELOPMENT POLICIES ACCORDING TO THE FEDERAL CONSTITUTIONS OF BRAZIL AND THE ROLE OF THE CONSTITUTIONAL FINANCING FUNDS AFTER 1988}

\begin{abstract}
This paper discusses the role of the Constitutional Financing Funds for the Brazilian regional dynamics. It is based on a theoretical and historical perspective of the regional problematic in the country, interpreting it as a result of the conflicts which have emerged since its colonial past and its accumulation standard. Both define the role of the country in the international division of labor and its social-spatial organization. It can be noted that the rigid territorial control, the
\end{abstract}


extreme exploitation of the workforce, and the public funds represent determining vectors in the way that the Brazilian regions are articulated to the logic of capitalist accumulation. The article is divided into five parts. The first one is the introduction to the paper. The second briefly considers the Brazilian regional problematic. The third discusses how the regional issue in Brazil is treated in the Federal Constitutions. The fourth analyzes the Constitutional Financing Funds. And the fifth draws conclusions.

Keywords | Brazil; Constitutional Financing Funds; regional development.

JEL-Code | O18; R12; R58.

\section{NOTAS SOBRE LAS POLÍTICAS DE DESARROLLO REGIONAL SEGÚN LAS CONSTITUCIONES FEDERALES DE BRASIL Y EL PAPEL DE LOS FONDOS CONSTITUCIONALES DE FINANCIAMIENTO POST-1988}

\section{Resumen}

Este trabajo discute el papel de los Fondos Constitucionales de Financiamiento en la dinámica regional brasileña. Parte de una perspectiva teórica e histórica de la problemática regional del país que la interpreta como siendo el resultado de los conflictos que emergen de su pasado colonial y de su padrón de acumulación. Ambos definen el papel del país en la división internacional del trabajo y su organización socio-espacial. Se observa que el control tenaz del territorio, la sobreexplotación de la fuerza de trabajo y los fondos públicos representan vectores determinantes del modo como las regiones brasileñas son articuladas a la lógica de la acumulación capitalista. El artículo está dividido en cinco partes. En la primera, se hace una presentación del trabajo. En la segunda, se hace una breve consideración de la problemática regional brasileña. En la tercera, se discute cómo la cuestión regional del Brasil es tratada en las Constituciones Federales. En la cuarta, es realizado un análisis de los Fondos Constitucionales de Financiamiento. En la quinta, se exponen las conclusiones.

Palabras-clave | Brasil; desarrollo regional; Fondos Constitucionales de Financiamiento.

Código JEL | O18; R12; R58.

\section{Introdução}

Este artigo busca discutir primordialmente, nas seções finais, o papel dos Fundos Constitucionais de Financiamento para a dinâmica regional brasileira. Parte de uma perspectiva teórica e histórica da problemática regional do país, interpretando-a como resultado dos conflitos que emergem desde seu passado colonial e das características de seu padrão de acumulação. Estes definem tanto seu papel na divisão internacional do trabalho quanto as formas de organização socioespacial que caracterizam um país com evidentes "desequilíbrios regionais".

No Brasil, o controle ferrenho do território, a superexploração da força de trabalho e os fundos públicos representam vetores determinantes na maneira como as regiões e as suas estruturas produtivas, em particular, são articuladas à lógica da acumulação capitalista em condições de dependência e 
subdesenvolvimento. Isto é determinante para a definição das funções, formas, processos e estruturas das regiões que serão socioespacialmente muito diferenciadas por todo país, o que define dinâmicas urbano-regionais também muito diferenciadas.

Este esforço se inicia com uma breve colocação da problemática regional no Brasil, interpretando-a como resultado das contradições - econômicas e sociais que marcam historicamente o movimento de sua sociedade e que deixaram marcas duradouras em sua organização espacial, perpetuando-lhe a desigualdade em sua dimensão territorial. Este é o tema do próximo tópico. Em seguida, apresenta-se como a questão regional foi incorporada às Constituições brasileiras, com particular destaque para os Fundos Constitucionais de Financiamento. Estes têm sua análise empírica e a discussão do seu papel para a dinâmica regional brasileira discutidas na seção seguinte, que antecede as considerações finais.

\section{Território, federação, trabalho e capital na problemática regional no Brasil}

Para pensar nossa problemática regional partimos de uma descrição sumária do que é o Brasil hoje: um país federativo desde a proclamação da República, formado pela União, 26 estados, um Distrito Federal e 5.570 municípios, todos definidos constitucionalmente como entes federados; uma economia de grande porte, embora periférica, subdesenvolvida e vulnerável - financeira e produtivamente $^{1}$ - na ordem internacional, a despeito de um certo consenso que se formou em torno da melhoria de seus indicadores (externos e internos) neste início do século XXI, melhoria essa que redundou em novas interpretações sobre o seu "desenvolvimentismo". Um país que é também um território continental, populoso e cindido por grandes injustiças sociais. Suas estruturas caracterizam-se por profundas diferenças socioespaciais entre suas regiões (e dentro delas) normalmente identificadas com o problema dos "desequilíbrios regionais" pela literatura pertinente - e por grande heterogeneidade econômica, mas também com grande diversidade regional. As origens desse mosaico devem ser buscadas nas heranças de seu passado colonial, que deixou marcas historicamente duradouras que influenciaram (e influenciam) os processos de organização socioespacial do país, em suas diferentes fases e escalas.

As características apresentadas acima são, no entanto, meras descrições que se restringem à aparência dos fatos e não informam as múltiplas e mutáveis relações sociais que estão ligadas a elas e cuja essência é a expressão do próprio movimento da sociedade e de suas contradições, dentro do marco geral do capitalismo. Portanto, é preciso ir além, e identificar o que tais características significam e quais

\footnotetext{
${ }^{1}$ Sobre a vulnerabilidade financeira e produtiva ver Carneiro (2008) e Cano (2012).
} 
determinantes estão no âmago de suas constituições e desdobramentos; quais elementos representam rupturas, mas, sobretudo, permanências sociais, políticas e econômicas que influenciam a dinâmica urbano-regional $e$ as formas de configuração territorial no Brasil.

Uma contribuição - teórica e metodológica - para compreensão do tema e elaboração de estudos de caso foi dada por Alejandro Rofman, para quem

la base fundamental de nuestra exposición indica que cada unidad regional se comporta como una formación social inserta en el esquema del sistema nacional [e internacional], participando y compartiendo características con ese sistema y poseyendo aspectos que resaltan como específicos. Una caracterización adecuada de la formación social nacional es indispensable para lograr una correcta individualización de procesos a escala de cada región; a la vez, una identificación precisa de las diversas instancias de la formación social regional - y su articulación - permite encontrar el modo de inserción del subespacio menor en el mayor (ROFMAN, 1974, p. 11).

Pensar nos termos de Rofman significa entender a imbricação concreta entre a organização espacial e os padrões de acumulação no Brasil em cada estágio de desenvolvimento da economia mundial; ou seja, uma imbricação entre as formas de articulação das estruturas internas de uma economia nacional com o movimento mais geral do imperialismo que reinventa, em cada etapa histórica, formas de dominação pela ação do capital internacionalizado que promove, em comum acordo com o capital associado nativo, o ajuste espacial (HARVEY, 2004, 2005, 2008) nas economias nacionais, especialmente naquelas subdesenvolvidas, a partir da refuncionalização dos usos e ocupações do território e das formas de exploração da força de trabalho, o que será decisivo para determinar o papel delas na divisão internacional do trabalho.

Observa-se, portanto, uma indissociável relação entre Economia, História e Geografia na determinação dos padrões de organização dos espaços nacionais e subnacionais, afinal, como lembra Moreira (1996, p. 38), "é a estrutura econômica da formação econômico-social que determina a organização espacial, mas é a conjuntura política que comanda seus movimentos". Conjuntura política que se manifesta eivada de contradições sociais e disputas, em cada momento histórico, em torno dos três elementos que movem a acumulação e o excedente econômico: a força de trabalho, o território e o capital. Portanto, o "espaço produzido só é explicável em função do processo que o engendrou e a forma criada só se revela pelo uso social a cada momento, este é que lhe atribui caráter ao qualificá-lo como valor de uso." (MOREIRA, 1996, p. 43).

Nesse encontro multidisciplinar, a organização do espaço (e neste caso especificamente do espaço nacional brasileiro) deve ser pensada a partir da 
estrutura de classes da sociedade e a forma como ela se espacializa, determinando diferentes estruturas regionais que se individualizam por lutas sociais que são, ao mesmo tempo, gerais - posto serem parte da mesma totalidade definida pelo movimento do capital -, mas também específicas, visto que esse movimento concretamente se realiza de maneira diferenciada de acordo com as singularidades econômicas, históricas e geográficas dos lugares ${ }^{2}$.

As características anteriormente mencionadas podem ser sintetizadas em três recorrências na história econômica do país, que são determinantes para entendermos seu padrão de organização espacial, e que nos permitem fazer mediações entre o movimento geral do capitalismo e seus efeitos sobre o espaço nacional e subnacional: a superexploração da força de trabalho; o uso predatório e o inegociável controle do território - rural e urbano - por parte de suas elites (e diretamente ligado a isso, o domínio dos fundos territoriais ${ }^{3}$ ); e o acesso aos fundos públicos, especialmente, após a proclamação da República, sem os quais a acumulação no país seria dificultada dada a natureza tacanha do capital nacional, dos limites de acumulação de suas elites regionais e da subordinação de ambos à ordem internacional. Sem o orçamento público, de um lado, e o forte controle sobre o uso do território, de outro - amalgamados por uma histórica e voraz exploração da força de trabalho e dos recursos naturais -, a fraca burguesia nativa teria muita dificuldade para participar - mesmo como sócia menor - da produção e distribuição da mais-valia que se realiza no espaço nacional.

Diversos intérpretes do Brasil, como Caio Prado Jr., Florestan Fernandes, Nelson Werneck Sodré e Celso Furtado, descreveram as formas intensiva, violenta e desumana com que a força de trabalho, corriqueiramente, é utilizada no país. Ruy Mauro Marini, com o conceito de superexploração do trabalho, relaciona esse aspecto ao caráter periférico das economias latinoamericanas que buscam compensar suas perdas por meio das trocas desiguais no comércio exterior com o aumento da exploração interna dos trabalhadores com base em três mecanismos: aumento da intensidade do trabalho; aumento da jornada de trabalho ou pela redução do fundo de consumo do trabalhador, podendo ocorrer simultaneidade entre eles.

Ou seja, o imperialismo configura na região um modo de produção que não está centrado no desenvolvimento de capacidade produtiva e na inovação tecnológica,

\footnotetext{
${ }^{2}$ A relação dialética parte-todo pode ser percebida nas jornadas de junho de 2013 no Brasil. Regionalmente, observava-se que muitas reivindicações eram de caráter nacional e estavam presentes em todas as cidades; outras, porém, assumiram caráter local e diziam respeito à luta de classes que ocorre nos lugares com especificidades próprias. Portanto, havia sempre uma pauta nacional articulada a questões locais/regionais.

${ }^{3}$ Termo foi tirado de Moraes (2002). Braga (2013, p. 4), com base neste autor, afirma que "os fundos territoriais podem ser entendidos como áreas de reserva ainda não incorporadas ao modo de produção dominante e, no caso da formação socioespacial brasileira, esta incorporação se dá por um processo contínuo de ocupação e valorização capitalista de novas áreas".
} 
mas essencialmente assentado na maior exploração do trabalho. Como resultado, na América Latina "nunca se chegou a conformar uma verdadeira economia industrial, que, definindo o caráter e o sentido da acumulação de capital, acarretasse em uma mudança qualitativa no desenvolvimento econômico." (MARINI, 1973, p. 166).

Essa superexploração não pode ser dissociada do segundo aspecto: o forte controle do território, e, ligado a ele, o controle dos fundos territoriais como aponta Moraes (2002). A depreciação da força de trabalho pode ser atestada tanto nas cidades quanto no campo, mas é nesse segundo que ela é mais evidente, em decorrência do peso econômico das atividades agrícolas e minerais - duas que se vinculam diretamente à natureza continental do país, e que determinam sua posição na divisão internacional do trabalho.

O avanço do agronegócio, por exemplo, impõe uma itinerância ${ }^{4}$ na agricultura que reproduz na fronteira toda violência que marca o controle da terra no Brasil. Essa itinerância tem importância decisiva no espraiamento da população pelo território e se caracteriza pelo uso predatório da terra, impondo uma forma de ocupação extensiva pela incorporação de novos rincões, e ao mesmo tempo uma ocupação intensiva pela ferocidade com que a força de trabalho e os recursos naturais são exauridos. Castilho (2012) e Delgado (2012) apresentam exemplos que são verdadeiras formas pré-capitalistas de exploração de trabalhadores nessas áreas aonde as elites impõem forte controle sobre a terra. Nas cidades, exemplos também não faltam: as jornadas de junho de 2013 denunciaram por todo o Brasil urbano as dificuldades cotidianas da vida e questionaram o uso e a destinação dos recursos públicos, normalmente direcionados para a iniciativa privada em detrimento de projetos e programas de abrangência social.

Os fundos públicos, por sua vez, também cumprem no Brasil papel decisivo no processo de acumulação, por financiarem tanto os investimentos privados quanto as políticas regionais de desenvolvimento. Além disso, representam importante amálgama dos arranjos federativos ao costurarem as relações intergovenamentais nos três (e entre os três) níveis de governo. Sem eles, não seria possível estabelecer minimamente uma pactuação que garantisse um equilíbrio, mesmo que instável, da Federação.

Em relação à acumulação privada, são bem conhecidos seus limites no Brasil, razão pela qual o BNDES historicamente foi determinante para a realização do investimento de longo prazo. Da mesma forma, o Banco do Nordeste, o Banco da Amazônia, o BDMG, o BDSC, o BANDES e todos os demais bancos estaduais de desenvolvimento que foram extintos cumpriram papel similar no

\footnotetext{
${ }^{4}$ Apesar de Furtado (1980) referir-se à itinerância como um processo característico da baixa produtividade e do uso de técnicas mais atrasadas na agricultura brasileira pré-1930, Cano (2001 e 2008) aponta que a mesma continuou, apesar da modernização neste setor pós-1970.
} 
financiamento das políticas regionais, fossem federais e/ou estaduais, a despeito dos seus alcances e da qualidade de seus resultados. A emergência dos bancos públicos se explica pela insuficiência do sistema bancário privado nacional para cumprir as tarefas que seus congêneres realizaram alhures para levar adiante o desenvolvimento industrial e a acumulação capitalista: centralização de recursos que pudessem ser utilizados no financiamento produtivo de longo prazo e capacidade para promover, financeiramente, a conglomeração de empresas. Com isso, caberia aos fundos públicos no Brasil cumprir, limitadamente, a clássica função de capital financeiro, intermediando o setor produtivo privado e o bancário estatal ${ }^{5}$.

Especificamente nas regiões mais atrasadas do país, eles foram estratégicos para as transformações de suas estruturas produtivas e para a articulação delas ao padrão industrial que emergiu no bojo da industrialização e da integração do mercado nacional, especialmente após a industrialização pesada impulsionada pelo Plano de Metas. Como as regiões menos dinâmicas não poderiam depender de sua estreita base interna de acumulação, os diversos fundos públicos (como FINOR, FINAM, FUNRES, FUNDAP, 34/18, dezenas de incentivos fiscais e financeiros estaduais, os Fundos Constitucionais de Financiamento, dentre tantos outros, inclusive fundos de natureza setorial) fizeram as vezes de financiadores da acumulação regional.

A disputa em torno deles marcaria esses espaços, afinal, eles garantiram às elites empresariais de todas as regiões - e não apenas das "atrasadas" - a possibilidade de realização de seus lucros, não obstante os limites delas para levar adiante a acumulação em bases produtivas modernas e eficientes. Em comum, todos esses fundos e mecanismos de desenvolvimento regional caracterizam-se fundamentalmente como instrumentos de acumulação descolados de qualquer projeto regional, quiçá nacional. Não foram poucos os casos de denúncia contra eles, colocando em relevo sua utilização como mecanismo de "acumulação por espoliação", por parte de determinados grupos de interesses regionais e nacionais.

Os Fundos Constitucionais de Financiamento aproximaram, ainda mais, os fundos públicos da problemática da questão regional brasileira. É deles que a próxima seção tratará.

\footnotetext{
${ }^{5}$ Sobre isso, ver análise de Oliveira (1998) para o Nordeste brasileiro.
} 


\section{A questão regional nas constituições brasileiras: o papel dos Fundos Constitucionais de Financiamento}

O artigo 159 da Constituição Federal de 1988 teve papel decisivo no ordenamento das relações federativas do país. Primeiro porque, ao determinar que $21,5 \%$ e $22,5 \%$ da arrecadação do Imposto sobre Renda e Proventos de Qualquer Natureza (IR) e do Imposto sobre Produtos Industrializados (IPI) fossem aplicados, respectivamente, nos Fundos de Participação dos Estados (FPE) e dos Municípios (FPM), criou condições objetivas para um processo de descentralização fiscal no país, o que aumentou, em princípio, a capacidade dos entes subnacionais na oferta de serviços e de políticas públicas.

Dentre essas possíveis políticas destacam-se, para compreensão da dinâmica regional brasileira, aquelas ligadas à atração de investimentos ${ }^{6}$ que teriam papel complementar (e até substituto) das tradicionais tentativas federais de redução das disparidades regionais que vinham sendo aplicadas desde os anos 1960. Embora esse esforço subnacional tenha se mostrado contestável em seus fundamentos e em seus resultados, como apontam diversos trabalhos sobre a guerra fiscal ${ }^{7}$ que indicam as possibilidades e limites dessas ações, especialmente quando sustentada pelo uso indiscriminado do ICMS, ele se tornaria crescente nos pós-1988 e teria papel destacado sobre a dinâmica regional brasileira, especialmente no período pós-Real, quando tais políticas foram importantes na desconcentração produtiva regional do país (CANO, 2008).

Segundo, porque, simultaneamente, também reservava 3\% daquela mesma arrecadação para aplicação em programas de financiamento junto ao setor produtivo cujos investimentos viessem a se localizar nas regiões Norte, Nordeste e Centro-Oeste, através de suas instituições financeiras de caráter regional, de acordo com os planos regionais de desenvolvimento, ficando assegurada ao semiárido nordestino a metade dos recursos destinados à sua região de origem, na forma que a lei estabelecesse.

Atualmente, os recursos podem ser aplicados em programas de financiamento ao setor produtivo não-governamental daquelas regiões, além dos municípios dos estados de Minas Gerais e Espírito Santo incluídos na área de atuação da SUDENE, através de suas instituições financeiras de caráter regional, e de acordo

\footnotetext{
${ }^{6}$ Segundo Rezende (2013), os critérios de rateio do FPE - que aumentou a base de arrecadação das regiões menos desenvolvidas - e as novas regras do ICMS reforçaram os orçamentos dos estados, especialmente os que se localizavam fora do Sul e Sudeste, criando estímulos a políticas subnacionais de atração de investimento, mais conhecidas como guerra fiscal.

${ }^{7}$ Sobre os limites das políticas locais de desenvolvimento regional baseadas na guerra fiscal, ver: Prado (2013); Rezende (2013); Macedo e Angelis (2013); Angelis (2012); Vieira (2012); Cardozo (2010); Prado e Cavalcanti (2000).
} 
com os planos regionais de desenvolvimento ${ }^{8}$. Pela legislação vigente, as diretrizes e prioridades para aplicação dos recursos cabem ao Ministério da Integração Nacional - MI, inclusive na orientação aos bancos para direcionar mais créditos para atividades correlacionadas à Política Nacional de Desenvolvimento Regional PNDR e aos planos de desenvolvimento sustentáveis para a Amazônia, Nordeste, Semiárido nordestino e Centro-Oeste que estão entre as prioridades da agenda regional dos governos pós-2003.

Resgatava-se com a criação dos Fundos Constitucionais de Financiamento do Norte, Nordeste e Centro-Oeste - FNO, FNE e FCO -, a obrigatoriedade da formulação, financiamento e execução de políticas regionais de desenvolvimento que foram abandonadas no contexto da crise dos anos 1980, o que abalou os macrofundamentos da economia brasileira e fez emergir tentativas subnacionais isoladas de substituir o papel que a União cumpria nesta órbita, conforme já destacado.

A destinação de 3\% do IR e do IPI restaurava o compromisso legal da União com o financiamento da política regional brasileira que fora suspenso nas Constituições de 1937 e 1967, mas que aparecia nos textos das de 1934 e 1946, ainda que numa perspectiva fortemente atrelada à visão mais tradicional que reforçava os interesses secularmente conservadores ligados à solução hidráulica no Nordeste (Constituições de 1934 e 1946) e de natureza genérica, mas com forte viés geopolítico, como a ideia de valorização da Amazônia (Constituição de 1946), que seria posta em prática principalmente na década de 1950, com a implantação de um conjunto de ações para a ocupação e o desenvolvimento dessa região que passaria a ser cada vez mais incorporada à lógica vigente do padrão de acumulação capitalista do país.

\footnotetext{
${ }^{8}$ A atuação do FNO, FNE e FCO se circunscreve a mais de 2.900 municípios, de 22 unidades federativas, que representam quase $28,0 \%$ do PIB brasileiro e $44,6 \%$ da população total do país. A renda per capita de sua área de abrangência é menos da metade da média do conjunto fora de sua competência.
} 
Quadro 1 - A questão regional nas constituições brasileiras

\begin{tabular}{|c|c|c|c|c|}
\hline $\begin{array}{c}\text { Constituição } \\
\text { Federal }\end{array}$ & Artigo(s) & $\begin{array}{l}\text { Questão } \\
\text { regional }\end{array}$ & Ação regional & Recursos previstos \\
\hline 1891 & - & Ausente & Ausente & Ausente \\
\hline 1934 & 177 & $\begin{array}{l}\text { Solução } \\
\text { hidráulica }\end{array}$ & $\begin{array}{c}\text { Defesa contra } \\
\text { os efeitos da } \\
\text { seca }\end{array}$ & $\begin{array}{l}4 \% \text { da receita } \\
\text { tributária da União } \\
\text { para financiamento de } \\
\text { um plano sistemático e } \\
\text { permanente de defesa } \\
\text { e assistência contra as } \\
\text { secas }\end{array}$ \\
\hline 1937 & - & Ausente & Ausente & Ausente \\
\hline 1946 & $198 ; 199$ & $\begin{array}{l}\text { Solução } \\
\text { hidráulica e } \\
\text { valorização e } \\
\text { ocupação da } \\
\text { Amazônia }\end{array}$ & $\begin{array}{l}\text { Defesa contra } \\
\text { os efeitos da } \\
\text { seca e } \\
\text { valorização e } \\
\text { ocupação da } \\
\text { Amazônia }\end{array}$ & $\begin{array}{c}3 \% \text { por cento da } \\
\text { renda tributária da } \\
\text { União para aplicação } \\
\text { no Nordeste e mesmo } \\
\text { valor para aplicação na } \\
\text { Amazônia }\end{array}$ \\
\hline 1967 & - & Ausente & Ausente & Ausente \\
\hline 1988 & 155 & $\begin{array}{l}\text { Integração } \\
\text { econômica e } \\
\text { expansão } \\
\text { produtiva } \\
\text { das regiões } \\
\text { "atrasadas" }\end{array}$ & $\begin{array}{c}\text { Ampliar a } \\
\text { base } \\
\text { econômica } \\
\text { das regiões } \\
\text { "atrasadas", } \\
\text { atraindo para } \\
\text { elas capital } \\
\text { produtivo }\end{array}$ & $\begin{array}{c}3 \% \text { do total } \\
\text { arrecadado do IR e do } \\
\text { IPI para aplicação no } \\
\text { setor produtivo das } \\
\text { Regiões Norte, } \\
\text { Nordeste e Centro- } \\
\text { Oeste }\end{array}$ \\
\hline
\end{tabular}

Fonte: Constituições Federais do Brasil. Elaboração própria.

O Quadro 1 explicita como a questão regional apareceu nas seis constituições republicanas do Brasil. Em metade delas, o tema esteve diretamente abordado, surgindo inicialmente na de 1934, após sua ausência na de 1891. Posteriormente, observa-se que a centralização autoritária (1937 e 1967, ambos períodos ditatoriais como lembra Cano [2008]) retira o tema que ressurge nos momentos subsequentes de redemocratização (1946 e 1988), reproduzindo na temática regional específica a ideia de movimento pendular - centralização $\mathrm{x}$ descentralização - tão presente na discussão sobre Federação e federalismo, da qual a questão regional é parte indissociável.

Três pontos chamam a atenção no referido Quadro 1. O primeiro diz respeito ao que ficava entendido em cada Constituição como a questão regional do país. Apesar dos esforços que se iniciaram com Getúlio Vargas, após a Revolução de 
1930, de quebrar o poder das elites regionais e de transformar questões locais/regionais em questões nacionais com fito a promover a industrialização (CANO, 1998), o fato é que tanto no texto de 1934 quanto no de 1946 observa-se a questão regional atrelada à tradicional visão que interpretava exclusivamente os problemas da atual região Nordeste do país como resultado das intempéries da seca. Essa visão - que sempre demandou uma solução com pesados investimentos e fundos públicos que beneficiavam as terras dos terra-tenentes da região escamoteava o caráter socialmente perverso do problema histórico de formação do complexo Nordestino [Furtado (1980); Cano (1990; 1998); Oliveira (1987)] que lhe determinava o atraso socioeconômico e as características de sua organização socioespacial.

Pari passu, naturalizar o "atraso" nordestino como consequência da falta d'água, possibilitava às elites locais apropriarem-se das políticas de combate à seca, ampliando seu poder de mando e de controle sobre a terra, sobre o dinheiro público e sobre a força de trabalho", como tão bem destacou Furtado no documento "Uma Política de Desenvolvimento Econômico para o Nordeste".

O segundo diz respeito à incorporação de toda a atual região Centro-Oeste à questão regional brasileira que até 1988, constitucionalmente, restringia-se ao Nordeste e à Amazônia, embora esta, para fins de planejamento, incorporasse parte de Goiás e do Mato Grosso ${ }^{10}$. A região Centro-Oeste, área que até os anos 1940 caracterizava-se por baixa densidade demográfica, é a que melhor sintetiza o esforço de inserção comercial do país pela combinação de fundos territoriais e fundos públicos; ela sintetiza a forma acelerada como as modernas atividades comandadas por grandes empresas globais modificaram-lhe o território, adaptando-o a suas necessidades de acumulação, redefinindo, assim, sua inserção na geografia econômica (interna e externa) pela substituição de antigas atividades baseadas em subsistência e na economia natural por modernas produções do agronegócio internacionalizado.

Impulsionada pelos investimentos do Plano de Metas e pelas políticas de colonização, sua ocupação seria intensificada pelos crescentes fluxos migratórios nas décadas de sessenta e setenta do século XX, que lhes proporcionaram altas taxas de crescimento demográfico - acima da média nacional -, que continuariam na década seguinte. Cumprindo o papel de "limpar a área" para a acumulação privada, o setor público promoveu fartamente as condições materiais e financeiras para que se operasse na região verdadeiro processo de "acumulação primitiva",

\footnotetext{
${ }^{9}$ Mais um evidente exemplo de superexploração da força de trabalho combinada à dominação e ao controle do território e dos fundos públicos.

${ }^{10}$ Pela lei no 1.806 de 06.01.1953, para fins de planejamento, parte do estado de Mato Grosso a norte do paralelo $16^{\circ}$, a do estado de Goiás a norte do paralelo $13^{\circ}$ e do Maranhão a oeste do meridiano de $44^{\circ}$ faziam parte da Amazônia.
} 
legitimando a concentração fundiária que se processou após os programas de colonização, bem como fortaleceu o caráter especulativo do uso da terra, componente sempre importante para compreensão da histórica itinerância da agricultura brasileira. Conforme destacado por Mueller (1990, p. 71), "o efeito da maior parte das políticas examinadas foi transferir recursos e patrimônios a indivíduos e grupos influentes, com reduzidos impactos sobre o desenvolvimento econômico e sobre o aumento de bem estar da maioria da população da região".

Este movimento promoveu completa redefinição do uso e ocupação do solo (rural e urbano) da região Centro-Oeste e, por consequência, reorientação de sua organização espacial ${ }^{11}$. Nela e na região Norte - cuja ocupação na segunda metade do século XX foi fortemente influenciada por projetos integrados com o exterior - fica evidente a tríade da acumulação subdesenvolvida e dependente: superexploração da força de trabalho; controle do território (e dos fundos territoriais) e uso dos fundos públicos, todos articulados a uma lógica normalmente determinada internacionalmente, mas dentro de um arranjo que abarca as frações do capital nacional que participam deste processo.

A criação do Fundo Constitucional de Financiamento do Centro-Oeste - FCO foi o desfecho que combinaria a associação dos fundos territoriais e dos fundos públicos à lógica de acumulação centroestina ao aprofundar sua especialização produtiva direcionada para atendimento dos mercados externos, especialmente os urbanos demandantes de fontes de matérias-primas e alimentos. O desempenho da economia chinesa foi particularmente decisivo para o crescimento acima da média nacional das atividades econômicas da região neste início de século XXI. Não por acaso, dos três Fundos, é o FCO o que apresenta maior valor médio das operações contratadas, o que indica maior porte das empresas que o acessam.

Portanto, a novidade de incorporação constitucional de todo Centro-Oeste à política regional brasileira parece responder muito mais aos movimentos nacional e internacional da acumulação capitalista do que a uma política de desenvolvimento regional que incorporasse as especificidades daquele espaço. Vale lembrar que os indicadores socioeconômicos desta região, mesmo se excluída a participação de Brasília que distorce os números, se assemelham mais aos do Sul e Sudeste do que aos do Norte e Nordeste. Não por acaso, inexiste no CentroOeste microrregião de baixa renda, segundo a tipologia da PNDR. Resta refletir se faz sentido, dado seu modelo de crescimento e seus indicadores socioeconômicos, haver um fundo específico e cativo para o desenvolvimento desta região ${ }^{12}$.

O terceiro ponto articula-se com os dois anteriores: o montante de recursos previstos para resolver a questão regional era significativamente maior do que aquele que passou a ser determinado na Constituição de 1988. E não apenas por

\footnotetext{
${ }^{11}$ Este e o parágrafo anterior foram retirados do texto de Macedo (2013).

${ }^{12}$ Sobre os limites do modelo assentado em commodities, ver Svanpa (2013).
} 
representar 3\% da receita tributária total para o combate a seca ${ }^{13}$ vis à vis o $3 \%$ do IR e do IPI como é no pós-1988, mas porque se exigia, constitucionalmente, que estados e municípios na área de abrangência do que seria definido a partir de 1936 como Polígono das Secas deveriam aplicar igual montante de recursos na assistência social. Portanto, abria-se mais uma fonte de recursos que poderia ser apropriada pelos mandonistas locais, reproduzindo a saga coronelismo, enxada e voto (LEAL, 1948).

Não obstante essa possibilidade de apropriação privada dos recursos por grupos de interesses locais e privados - que de fato ocorreu -, estava colocada explicitamente a obrigatoriedade de oferta de um montante financeiro não desprezível dos três diferentes níveis de governo que poderiam alterar os padrões socioeconômicos e espaciais da região; implicitamente, ficava estabelecido uma coordenação nas ações dentro do Polígono das Secas, indicando que a solução dos históricos problemas da região dependiam de um esforço multiescalar - para usar um termo atual, porém estranho à época - e de cooperação federativa. Essa perspectiva se perdeu na Constituição de 1988.

Nas palavras textuais do $\int 3^{\circ}$, do artigo 177 da Carta de 1934, "os Estados e Municípios compreendidos na área assolada pelas secas empregarão quatro por cento da sua receita tributária, sem aplicação especial, na assistência econômica à população respectiva". No texto de 1946, desaparecia a obrigatoriedade dos municípios aplicarem a mesma quantia da União (3\%), mas permanecia a determinação para os estados. Na Amazônia, ao contrário, estados, territórios e municípios deveriam reservar 3\% das suas rendas tributárias. No entanto, tais recursos, segundo o texto constitucional de 1946, "serão aplicados por intermédio do Governo Federal", o que indicava que a região amazônica era tratada dentro de uma visão geopolítica que exigia a centralização das ações e dos recursos a partir da União, o que não era de surpreender dado o papel que ela cumpre como área de fronteira e portadora de grandes fundos territoriais passíveis de apropriação para futuras atividades econômicas, inclusive por sua imensa biodiversidade e por deter o maior reservatório de recursos hídricos do planeta.

Fosse mantida na Constituição Federal de 1988 a mesma dotação prevista na de 1946, excluindo as obrigações estaduais para com o financiamento de políticas de desenvolvimento regional em montante equivalente aos recursos federais que desapareceram na última Carta Magna, observa-se pela Tabela 1 que, entre 1994 e 2013, o total de recursos disponíveis para o financiamento da política de desenvolvimento regional no país seria hoje $21 \%$ maior (Coluna H da Tabela 1) ou $\mathrm{R} \$ 1,35$ bilhão/ano a mais. Somadas as contribuições estaduais, esse montante seria ainda maior.

\footnotetext{
${ }^{13} \mathrm{Na}$ verdade, a Constituição de 1934 determinava 4\% e a de 1946, 3\%.
} 
Nestes termos, observa-se que do ponto de vista do financiamento houve uma desvalorização desta política ${ }^{14}$ vis à vis ao que estava colocado anteriormente. Desvalorização que se agrava quando se considera o esforço de recentralização praticado pela União a partir dos anos 1990 e que lhe aumentou a arrecadação com o crescimento das receitas que não estão vinculadas constitucionalmente. Com isso, tanto o FNO, FNE e o FCO quanto o FPM e o FPE são afetados. No caso desses dois últimos, acirram-se as tensões federativas já fortemente abaladas pelos critérios de rateio, particularmente no caso do $\mathrm{FPE}^{15}$.

\section{Tabela 1 - Brasil: IR, IPI e receita tributária (em $R$ \$ milhão) ${ }^{16}$}

\begin{tabular}{ccccccccc}
\hline Ano & A - IR & B - IPI & $\begin{array}{c}\text { C - B/A } \\
(\%)\end{array}$ & $\begin{array}{c}\text { D - Rec. } \\
\text { Tributária }\end{array}$ & $\begin{array}{c}\text { E - } \\
(A+B) / C \\
(\%)\end{array}$ & $\begin{array}{c}\text { F - 3\% } \\
\text { IPI+IR }\end{array}$ & $\begin{array}{c}\text { G - } 3 \% \\
\text { Rec. Trib. }\end{array}$ & $\begin{array}{c}\text { H - E/D } \\
(\%)\end{array}$ \\
\hline 1994 & 60.500 & 37.274 & 61,6 & 137.677 & 71,0 & 2.933 & 4.130 & 1,41 \\
1995 & 111.544 & 56.940 & 51,0 & 206.039 & 81,8 & 5.055 & 6.181 & 1,22 \\
1996 & 121.569 & 59.325 & 48,8 & 211.176 & 85,7 & 5.427 & 6.335 & 1,17 \\
1997 & 120.359 & 59.308 & 49,3 & 215.067 & 83,5 & 5.390 & 6.452 & 1,20 \\
1998 & 147.270 & 56.947 & 38,7 & 244.935 & 83,4 & 6.127 & 7.348 & 1,20 \\
1999 & 135.277 & 47.681 & 35,2 & 224.556 & 81,5 & 5.489 & 6.737 & 1,23 \\
2000 & 131.561 & 48.062 & 36,5 & 215.437 & 83,4 & 5.389 & 6.463 & 1,20 \\
2001 & 144.963 & 46.717 & 32,2 & 227.230 & 84,4 & 5.750 & 6.817 & 1,19 \\
2002 & 148.222 & 36.239 & 24,4 & 211.681 & 87,1 & 5.534 & 6.350 & 1,15 \\
2003 & 150.183 & 32.660 & 21,7 & 209.892 & 87,1 & 5.485 & 6.297 & 1,15 \\
2004 & 146.827 & 34.218 & 23,3 & 209.079 & 86,6 & 5.431 & 6.272 & 1,15 \\
2005 & 180.709 & 38.625 & 21,4 & 248.911 & 88,1 & 6.580 & 7.467 & 1,13 \\
2006 & 188.979 & 41.420 & 21,9 & 262.163 & 87,9 & 6.912 & 7.865 & 1,14 \\
2007 & 206.376 & 44.784 & 21,7 & 286.139 & 87,8 & 7.535 & 8.584 & 1,14 \\
2008 & 229.026 & 48.217 & 21,1 & 333.256 & 83,2 & 8.317 & 9.998 & 1,20 \\
2009 & 230.086 & 36.790 & 16,0 & 320.728 & 83,2 & 8.006 & 9.622 & 1,20 \\
2010 & 228.222 & 44.621 & 19,6 & 337.531 & 80,8 & 8.185 & 10.126 & 1,24 \\
2011 & 240.531 & 46.927 & 19,5 & 386.287 & 74,4 & 8.624 & 11.589 & 1,34 \\
2012 & 248.649 & 44.916 & 18,1 & 366.948 & 80,0 & 8.807 & 11.008 & 1,25 \\
2013 & 259.614 & 42.706 & 16,4 & 376.042 & 80,4 & 9.070 & 11.281 & 1,24 \\
\hline Total & 3.430 .467 & 904.377 & 26,4 & 5.230 .774 & 82,9 & 130.045 & 156.923 & 1,21 \\
\hline
\end{tabular}

Fonte: STN. Elaboração Própria.

\footnotetext{
${ }^{14}$ Evidentemente que essa afirmação deve ser relativizada ante a descentralização. Mas esta desembocou no acirramento da guerra fiscal. Um indicativo do enfraquecimento/desvalorização da política regional.

${ }^{15}$ Rezende (2013) e Prado (2013) apontam as tensões que emanam dos critérios de rateio do FPE.

${ }^{16}$ A preços constantes de 2013.
} 
Outro aspecto que afeta desfavoravelmente o volume de recursos repassados de Constitucionais de Financiamento é o uso do IPI como instrumento de estímulo à demanda interna posto em marcha desde o primeiro governo Lula. Isso é particularmente visível em 2009, quando a arrecadação deste imposto sofreu queda de 23,7\% após decisão federal de reduzir as alíquotas de um grupo de produtos - linha branca e automóvel especialmente - como resposta à crise internacional. Desde aquele ano, a arrecadação do IPI ficou abaixo da verificada em 2008; dos últimos seis anos, apenas o de 2011 e o de 2008 apresentaram maior arrecadação do que o ano de 2007.

Observando a série da Tabela 1, desde 1994, em termos reais, o crescimento da arrecadação do IPI pouco evoluiu (Coluna B). Ao contrário, a média anual de arrecadação entre 1994 e 2003 foi 13,7\% maior ( $\$ 48,1$ bilhões) do que a verificada entre 2004 e 2013 (R $\$ 42,3$ bilhões). Esse baixo desempenho arrecadatório reflete não apenas o manejo do IPI como instrumento para aquecimento da demanda interna, mas, também, se deve aos efeitos da abertura comercial dos anos 1990 que impôs queda em determinados impostos para manter a competitividade da indústria no país frente à concorrência externa. Reflete, também, as consequências mais recentes da desindustrialização ${ }^{17}$ que está reduzindo a base de arrecadação da indústria brasileira, especificamente a do $\mathrm{IPI}^{18}$.

O baixo crescimento da arrecadação desse imposto foi compensado pelo crescimento do IR, especialmente neste início de XXI, como pode ser visto na referida Tabela 1 (Coluna A). A retomada do crescimento após 2003, a expansão da renda interna e o menor reajuste nas faixas de tributação da renda elevaram a participação do IR. Com isso, seu peso - relativo e absoluto - como fonte de financiamento dos fundos públicos constitucionais amplia-se: em 1994, o montante de IR era 61,2\% maior do que o de IPI. Essa diferença aumenta continuamente até atingir 273,3\% em 2013, a maior de toda a série.

Entre os limites de crescimento de um (IPI) e a elevação do outro (IR), o fato é que houve significativo aumento dos recursos dos Fundos Constitucionais de Financiamento disponíveis para apoio às atividades econômicas a partir da primeira década deste século, motivada tanto pelo aumento dos repasses do governo federal - em decorrência do crescimento da arrecadação, quanto por

\footnotetext{
${ }^{17}$ Sobre uma visão crítica da desindustrialização no Brasil, ver Cano (2012). Sampaio (2013) apresenta uma boa síntese do debate.

18 Esta desindustrialização eleva estatisticamente a "concentração produtiva" em bens de consumo não duráveis e de baixa ou média intensidade tecnológica. Nesses setores, a elasticidade de arrecadação é inferior em relação aos setores de bens de duráveis e de bens de capital e aos intensivos em tecnologia, o que indica, também, problemas futuros no crescimento da arrecadação de IPI.
} 
mudanças na forma de gestão desses Fundos. Eles se tornaram a principal fonte de financiamento da política regional brasileira, especialmente a PNDR, instituída legalmente em 2007. É sobre isso que o próximo tópico tratará.

\section{O papel dos Fundos Constitucionais de Financiamento para a dinâmica regional brasileira: uma análise empírica preliminar}

Macedo e Matos (2007 e 2008a) destacaram que os FNO, FNE e FCO despertam interesse pela sua importância como modalidade de crédito de desenvolvimento que pode conduzir ao melhor aproveitamento das potencialidades regionais, embora não devessem ser instrumentalizados sem uma política nacional de desenvolvimento regional. Este problema deixou de existir - pelo menos retoricamente - a partir de 2007, quando passaram a ser a principal fonte de financiamento da PNDR, instituída pelo Decreto federal $\mathrm{n}^{\circ}$ 6.047, de 22 de fevereiro daquele ano. Com esta política, o Ministério da Integração vincularia os financiamentos dos três Fundos aos objetivos dela, com esforços para direcionar recursos para as três áreas - Estagnadas, de Baixa Renda e Dinâmicas - definidas como prioritárias na $\mathrm{PNDR}^{19}$.

Vale lembrar ainda, como apontam os autores, que o montante de recursos disponibilizados por eles é relevante, embora insuficiente para fazer frente aos históricos problemas das regiões-alvo. $\mathrm{Na}$ verdade, representam ingressos permanentes e contínuos para as regiões Norte, Nordeste e Centro-Oeste e que não substituem outras fontes de financiamento e os gastos do Governo Federal. Seu caráter obrigatório e sua arquitetura legal os protegem de influências conjunturais de contingenciamento, o que os tornam um fluxo adicional e seguro de recursos destinados às três regiões, embora restritos, exclusivamente, aos investimentos privados.

\footnotetext{
19 Conforme explicitado oficialmente, "os Fundos Constitucionais são hoje os principais instrumentos de que dispõe a PNDR. São os instrumentos mais efetivos, não só pelo fato de eles não estarem sujeitos a contingenciamento, mas também pelo volume de recursos disponíveis. A PNDR tem outros instrumentos, como os incentivos fiscais e os Fundos de Desenvolvimento (FDA e FDNE). Falando no porte dos beneficiários, a Lei que criou os Fundos Constitucionais estabelece tratamento prioritário para os empreendedores de menor porte. A PNDR recomenda tratamento prioritário para os empreendimentos localizados nas microrregiões classificadas como de baixa renda, estagnada e dinâmica. A PNDR introduziu um novo e muito importante conceito, no sentido de se trabalhar o território e dar um tratamento prioritário para levar o crédito, em primeiro lugar, às microrregiões consideradas como de menor renda e de menor dinamismo". (MINISTÉRIO DA INTEGRAÇÃO, 2009, p. 9). Sobre a avaliação da PNDR, ver: Pereira (2009) e Vargas (2013).
} 
O Gráfico 1 apresenta a evolução dos valores contratados pelos três Fundos, desde 1995, e no Gráfico 2 encontra-se a evolução do número de operações realizadas. Neles observam-se tanto seu crescimento operacional, quanto o aumento de seu potencial financeiro e de alavancagem para novos investimentos.

Gráfico 1 - Fundos Constitucionais de Financiamento: evolução dos valores contratados $^{20}$

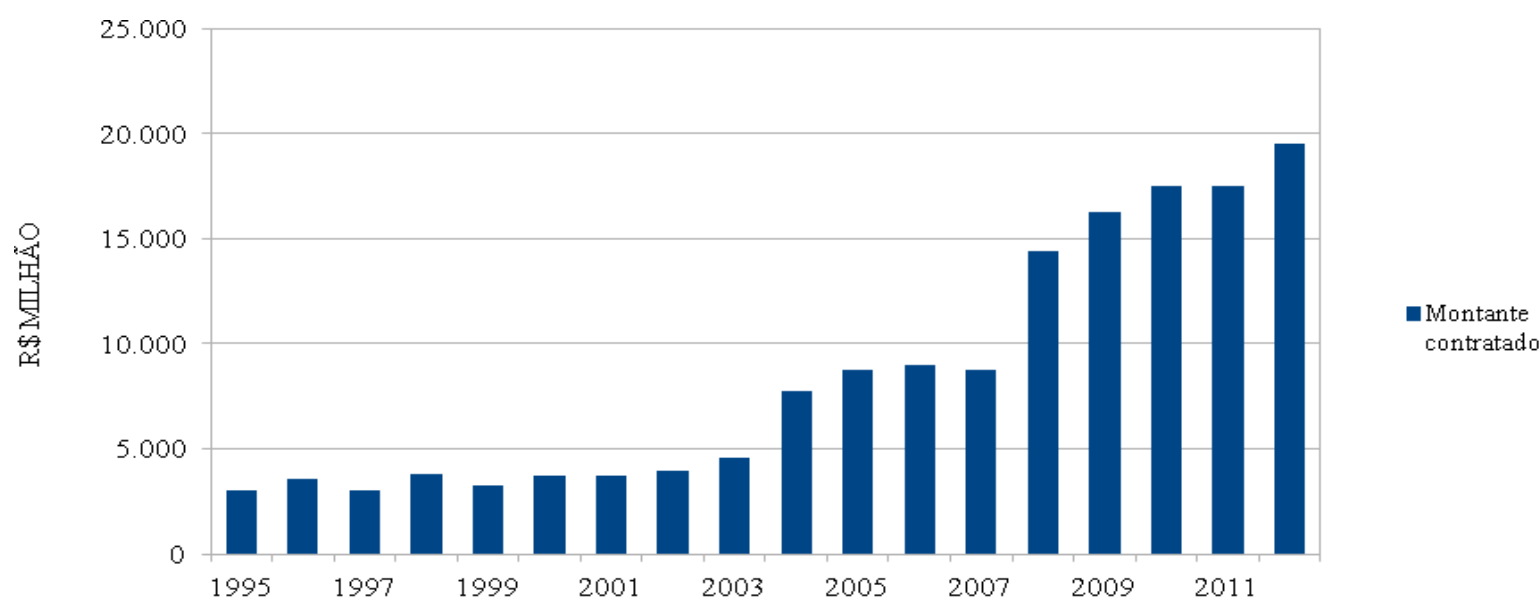

Fonte: MI. Elaboração própria.

Gráfico 2 - Fundos Constitucionais de Financiamento: evolução do número de operações contratadas

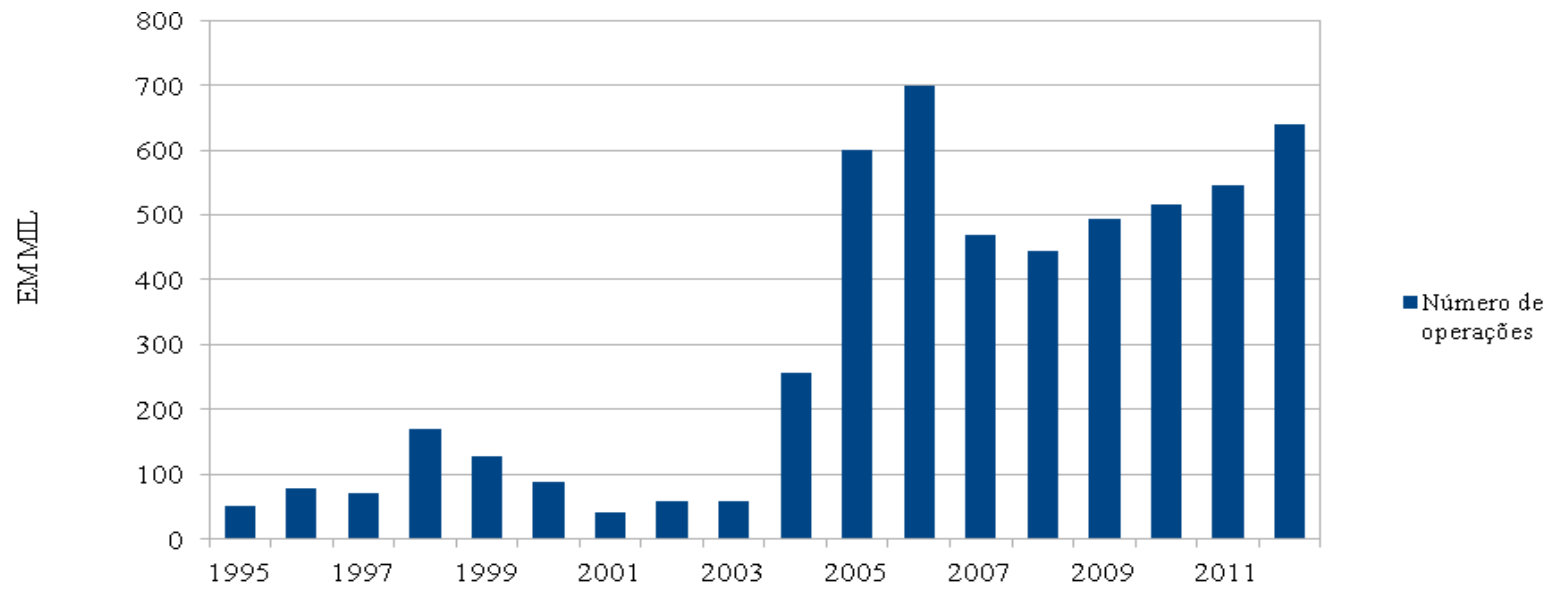

Fonte: MI. Elaboração própria.

Em relação à operacionalização, há duas fases distintas. Uma, de funcionamento aquém das potencialidades dos três Fundos, que vai até 2002; outra de 2003 em

\footnotetext{
${ }^{20}$ A preços constantes de 2010.
} 
diante, quando o número de operações e o montante das contratações cresceram continuamente. $\mathrm{Na}$ primeira, estima-se que o montante médio anual do valor das contratações foi de $\mathrm{R} \$ 3,6$ bilhões $^{21}$ e o número médio anual de operações de quase 56 mil. No entanto, há diferenças nesse período. Até 1994, o número de operações foi em média quase $16 \mathrm{mil} / \mathrm{ano}$, enquanto nos oito anos seguintes passou para quase $86 \mathrm{mil} /$ ano. Até 2002, o repasse anual da Secretaria do Tesouro Nacional foi sempre maior do que o montante de recursos contratados; a partir de 2003, isso se inverte e em todos os anos os valores contratados ficaram acima dos repasses. Nesse segundo período, o número de operações - com média anual de 473 mil - e o montante contratado - com média anual de $\mathrm{R} \$ 12,7$ bilhões cresceram significativamente.

O Gráfico 3 apresenta a relação entre o que foi repassado pelo STN e o que foi contratado pelos três Fundos. Nele fica nítida a diferença entre os dois períodos, comentado acima.

\section{Gráfico 3 - Fundos Constitucionais de Financiamento: relação entre os valores contratados e os repasses do STN}

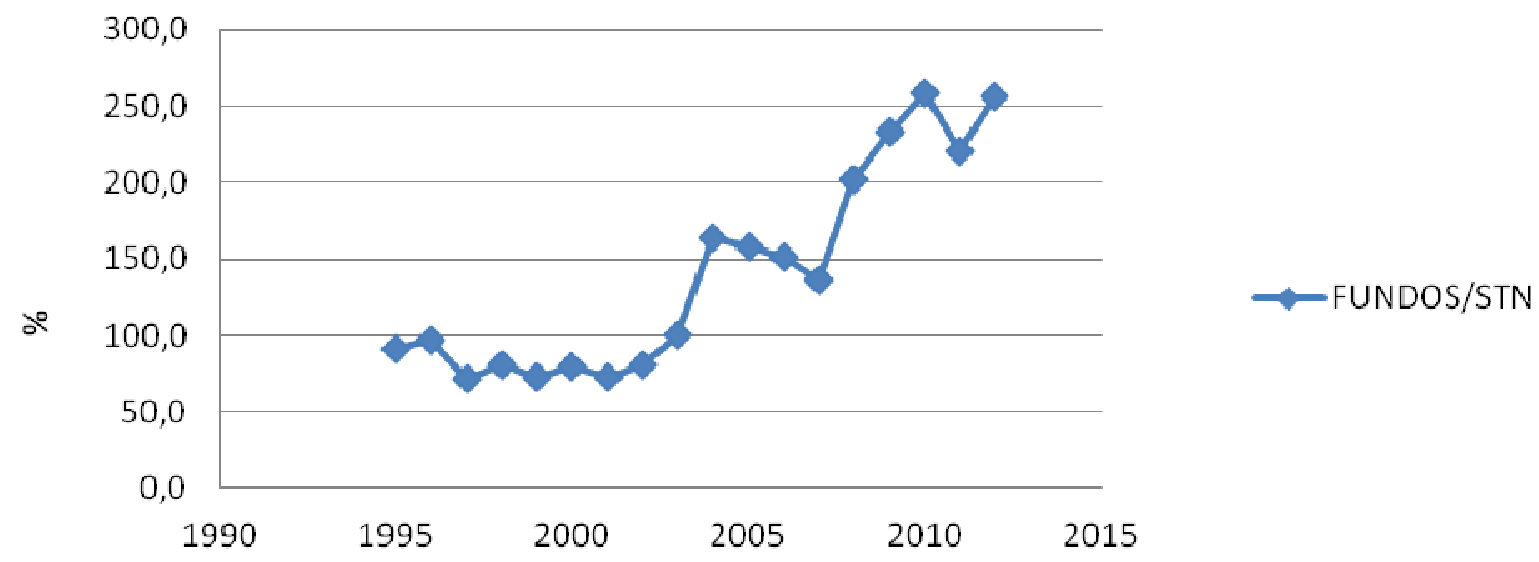

Fonte: MI. Elaboração própria.

A diferença entre um e outro período tem algumas razões, mas a principal está relacionada ao desempenho da economia, que foi bastante insatisfatório nos anos 1990, quando a abertura comercial e financeira provocou processo de ajuste defensivo das empresas por todo país, com redução dos investimentos, o que acarretou baixo crescimento econômico. A demanda pelos recursos dos Fundos encontra-se diretamente ligada às decisões de investimento por parte dos potenciais tomadores que agem de acordo com o "espírito empresarial" privado, portanto em sintonia com a situação do mercado que, naquela conjuntura de

\footnotetext{
${ }^{21}$ A preços constantes de 2010.
} 
regulação neoliberal, era bastante desfavorável. Aliado a isso, problemas de operacionalização dos recursos também se manifestaram durante todo esse período, o que dificultava a circulação deles.

A retomada do crescimento da economia brasileira pós-2003, puxada tanto por fatores externos - crescimento chinês e elevação dos preços internacionais das commodities - e internos - aumento da renda média dos brasileiros; maior formalização do mercado de trabalho; aumento do gasto público; elevação do salário mínimo acima da inflação; e ampliação dos programas sociais - favoreceu a retomada dos investimentos e explica, em parte, o forte aumento da demanda pelos recursos dos três Fundos (Gráficos 1 e 2).

Além da conjuntura favorável, outros elementos também podem ser apontados como responsáveis pelo salto das operações e do volume de recursos contratados a partir de 2003: a) novas modalidades de créditos (inclusive incorporação de operações do PRONAF e financiamento a empreendimentos comerciais e de serviços) e ações mais pró-ativas dos bancos gestores dos Fundos; b) esforço para diminuir a inadimplência e recuperar as dívidas dos devedores; c) aumento da capilaridade das ações; d) redução das taxas de juros. $\mathrm{Na}$ condição de fundo rotativo, os esforços destacados são importantes, especialmente b), que possibilita o aumento dos recursos disponíveis. Isto permite, inclusive, avançar nos esforços a) e c). Ademais, cabe destacar que os resultados da remuneração dos recursos não-aplicados em um período, descontadas as despesas operacionais, podem ser reinvestidos no período seguinte.

Como lembra Cintra, a dinâmica das carteiras de operações está relacionada com:

a) a demanda por crédito pelos agentes econômicos (relacionada com as características da economia nacional e de cada região); b) o grau de inadimplência dos tomadores de crédito, com impactos sobre a capacidade de se realizar novas operações; c) a política de concessão de créditos (a oferta) pelas instituições financeiras, relativamente a outras alternativas de aplicação dos recursos; d) a disponibilidade de recursos para conceder créditos a taxas de juros compatíveis com os empreendimentos; e) descompasso entre tempo de arrecadação e de inversão (investimentos de longa duração); e) possíveis dificuldades de acesso provenientes da capilaridade das instituições financeiras etc. (CINTRA, 2007, p. 36-37).

Não é possível avaliar os Fundos sem discutir a PNDR. Esta representou avanço no arcabouço de política de desenvolvimento regional no país por três razões principais: 1) superou a velha concepção de que os problemas regionais localizavam-se nas macrorregiões Norte e Nordeste, embora estas sejam as que apresentam, de fato, os piores indicadores socioeconômicos no país. Para tanto, definiu tipologias à escala microrregional com base na renda per capita e variação 
do PIB, o que explicitou o fato de que em todo país - inclusive no Sul e Sudeste há áreas deprimidas, estagnadas e de baixa renda que também merecem atenção; 2) definiu a diversidade como um ativo a ser usado favoravelmente no desenvolvimento das regiões; 3) superou a velha tradição bottom up de formulação de política regional definida pelo governo federal, sem aderir, no entanto, à concepção localista que tensionaria, ainda mais, os conflitos federativos no país.

Quando se olha, no entanto, para o financiamento dessa política - e este é um ponto nevrálgico para sua eficácia - ficam evidentes suas dificuldades. Toda arquitetura financeira da política de desenvolvimento regional no Brasil fora concebida antes dos anos 1990. Os principais instrumentos foram estruturados para atuarem macrorregionalmente nas tradicionais "regiões-problema". Basta verificar na página do MI as atribuições da Secretaria de Fundos Regionais e Incentivos Fiscais (SFRI), criada em 2001, que é a "responsável por administrar, em conjunto com outras Instituições, os recursos dos Fundos Constitucionais de Financiamento do Norte (FNO) do Nordeste (FNE) e do Centro-Oeste (FCO), dos Fundos de Desenvolvimento da Amazônia (FDA), do Nordeste (FNE) e do Centro Oeste (FDCO), dos Incentivos Fiscais e dos Fundos de Investimento da Amazônia (FINAM) e do Norte (FINOR)"22. O trecho é autoexplicativo e não deixa dúvidas quanto à distância das prioridades da PNDR - concebida para atuar com ênfase na escala microrregional e que toma todo território como sua área de atuação em múltiplas escalas - e a possibilidades de financiamento para além das três regiões (Norte, Nordeste e Centro-Oeste).

Por essa razão, a constituição de um Fundo Nacional de Desenvolvimento Regional - FNDR ${ }^{23}$ foi, desde a concepção inicial da PNDR, considerada estratégica para sua execução em múltiplas escalas e com participação dos entes federativos. Entretanto, conforme consta em documento do MI, "incluída no bojo da PEC da Reforma Tributária, após uma série de emendas e recortes, a proposta de criação do FNDR se perdeu e se inviabilizou no quadro de impasses da própria PEC" (SECRETARIA DE DESENVOLVIMENTO REGIONAL, 2012, p. 20).

Portanto, as dificuldades da reforma tributária - uma velha demanda da sociedade e que poderia reordenar as fontes e usos dos fundos públicos - tornaram-se óbice para se avançar neste ínterim. Qualquer reforma tributária pressupõe alterar a correlação de forças da Federação e estabelecer outra pactuação com definição de perdedores e vencedores, nacional e regionalmente. Isto esbarraria, evidentemente,

\footnotetext{
22 http://www.integracao.gov.br/web/guest/apresentacao_sfri. Capturado em 14 de abril de 2014.

${ }^{23}$ É nítida a influência da experiência da União Europeia na concepção deste fundo. Sobre a experiência de política de desenvolvimento regional da UE, ver Diniz (2007).
} 
na reação dos grupos de interesses hegemônicos que atuam por dentro dos fundos públicos e que exercem forte poder político local ${ }^{24}$.

A intenção da PNDR de ampliar a destinação dos recursos para as microrregiões de Baixa Renda, Estagnadas e Dinâmicas não encontra correspondência na realidade. A Tabela 3 mostra que nos anos pós-2007 foi mínima a perda de participação das áreas de Alta Renda que são justamente aquelas não priorizadas pela Política. Apenas no Nordeste houve uma desconcentração, enquanto os valores contratados pelos FNO e FCO ampliaram a participação das microrregiões de Alta Renda, seguindo as indicações do mercado. No caso do Centro-Oeste não apenas houve aumento de participação como se observa um percentual muito alto de recursos naquelas áreas de mais elevada renda: 42,1\% contra 21,3\% no Nordeste e 11,1\% no Norte. Conforme já destacado, é no Centro-Oeste que ocorre com mais intensidade, desde o último quarto século passado, combinação dos fundos públicos com fundos territoriais na organização espacial, a partir das transformações de sua base econômica.

Quando se faz o corte por porte de município, segundo tamanho populacional, observa-se crescimento na participação dos maiores (acima de 500 mil - ver Tabela 4A), especialmente no século XXI, o que indica o caráter espacialmente concentrador dos Fundos. São esses municípios os que apresentam maiores externalidades, melhores condições infraestruturais e maior adensamento econômico. Por essa razão, quando se faz o corte também entre atividades majoritariamente urbanas (indústria, serviços e comércio) e atividades majoritariamente rurais (agricultura, pecuária, extrativa e pesca) há diferenças importantes.

As primeiras - que apresentam maior poder de encadeamento sobre as estruturas produtivas e refletem e são reflexos de processos que promovem maior diversificação produtiva - localizam-se precipuamente em municípios que atingem certo grau de urbanização, sobretudo no caso do terciário. Em 2012, era praticamente igual a participação dos municípios menores (abaixo de 100 mil habitantes) e os médios e grandes na distribuição dos valores contratados (Tabela 4B). Importante destacar que em 2000 a participação dos menores era de 27,1\%. Provavelmente, esse positivo crescimento na participação relativa reflete a maior interiorização da atividade econômica e seus efeitos já destacados por Macedo (2010a e 2010b), especialmente maior urbanização, que cria oportunidades adicionais de investimentos neles, sobretudo neste início de século XXI, quando o avanço da extrativa mineral e da agricultura tecnificada de larga escala exigiram investimentos fora do core econômico do país. As contratações em atividades

\footnotetext{
${ }^{24}$ Não deixa de ser ilustrativo o fato de os governos estaduais e municipais nunca terem abraçado a PNDR, conforme consta no documento da Secretaria de Desenvolvimento Regional (2012).
} 
majoritariamente rurais (Tabela 4C) concentram-se nos municípios pequenos, sendo insignificante nos grandes (acima de 500 mil habitantes) e nos médios (entre 100 e 500 mil habitantes). 
Tabela 3 - FNO, FNE e FCO: distribuição dos valores contratados, segundo tipologia da PNDR (em \%)

\begin{tabular}{|c|c|c|c|c|c|c|c|c|c|c|c|c|c|c|c|}
\hline \multirow[b]{2}{*}{ Ano } & \multicolumn{4}{|c|}{ Total } & \multicolumn{4}{|c|}{$\mathrm{FNO}$} & \multicolumn{4}{|c|}{ FNE } & \multicolumn{3}{|c|}{$\mathrm{FCO}$} \\
\hline & $\begin{array}{c}\text { Alta } \\
\text { Renda }\end{array}$ & Dinâmica & $\begin{array}{l}\text { Baixa } \\
\text { Renda }\end{array}$ & Estagnada & $\begin{array}{c}\text { Alta } \\
\text { Renda }\end{array}$ & Dinâmica & $\begin{array}{l}\text { Baixa } \\
\text { Renda }\end{array}$ & Estagnada & $\begin{array}{c}\text { Alta } \\
\text { Renda }\end{array}$ & Dinâmica & $\begin{array}{l}\text { Baixa } \\
\text { Renda }\end{array}$ & Estagnada & $\begin{array}{c}\text { Alta } \\
\text { Renda }\end{array}$ & Dinâmica & Estagnada \\
\hline 2007 & 25,0 & 26,2 & 14,4 & 34,4 & 7,4 & 29,3 & 27,7 & 35,6 & 25,3 & 25,5 & 17,7 & 31,5 & 34,0 & 25,8 & 40,1 \\
\hline 2008 & 25,3 & 27,0 & 12,5 & 35,3 & 11,4 & 26,9 & 28,3 & 33,5 & 24,6 & 27,4 & 13,9 & 34,2 & 35,1 & 26,2 & 38,8 \\
\hline 2009 & 23,1 & 26,6 & 10,5 & 39,8 & 6,6 & 25,5 & 12,6 & 55,3 & 25,1 & 25,8 & 13,4 & 35,6 & 30,3 & 29,9 & 39,8 \\
\hline 2010 & 24,8 & 30,1 & 9,9 & 35,3 & 7,7 & 26,1 & 20,1 & 46,2 & 22,8 & 34,3 & 11,4 & 31,5 & 39,8 & 22,0 & 38,2 \\
\hline 2011 & 25,8 & 29,7 & 9,4 & 35,1 & 7,6 & 40,1 & 10,9 & 41,3 & 22,2 & 30,1 & 13,8 & 33,9 & 39,4 & 25,3 & 35,3 \\
\hline 2012 & 24,8 & 24,4 & 10,2 & 40,6 & 11,1 & 21,8 & 13,8 & 53,2 & 21,3 & 27,7 & 13,8 & 37,2 & 42,1 & 19,6 & 38,3 \\
\hline
\end{tabular}

Fonte: MI. Elaboração própria.

Tabela 4A - FNO, FNE e FCO: distribuição total dos valores contratados, segundo tamanho populacional dos municípios (em \%)

\begin{tabular}{|c|c|c|c|c|c|c|c|c|c|c|c|c|c|c|c|c|c|c|c|c|c|c|c|c|}
\hline \multirow{2}{*}{ Porte do município } & \multicolumn{24}{|c|}{ Ano } \\
\hline & 1989 & 1990 & 1991 & 1992 & 1993 & 1994 & 1995 & 1996 & 1997 & 1998 & 1999 & 2000 & 2001 & 2002 & 2003 & 2004 & 2005 & 2006 & 2007 & 2008 & 2009 & 2010 & 2011 & 201 \\
\hline$<5 \mathrm{mil}$ & 0,0 & 3,5 & 2,0 & 3,7 & 5,8 & 7,0 & 4,1 & 3,7 & 5,7 & 4,6 & 6,1 & 5,7 & 7,8 & 10,4 & 6,5 & 6,3 & 7,9 & 6,9 & 8,1 & 7,7 & 6,3 & 5,6 & 4,9 & 5,7 \\
\hline$>5$ mil e & 0,0 & 7,6 & 9,7 & 14,7 & 14,6 & 8,7 & 9,7 & 9,8 & 8,6 & 12,1 & 13,2 & 15,4 & 13,4 & 12,4 & 9,0 & 9,9 & 9,2 & 9,5 & 9,4 & 9,4 & 7,9 & 8,1 & 11,4 & 8,5 \\
\hline$>10$ mil e & 2,6 & 13,7 & 36,6 & 29,6 & 25,2 & 38,8 & 20,0 & 23,4 & 24,1 & 25,1 & 23,9 & 20,1 & 20,5 & 23,3 & 17,5 & 15,8 & 20,0 & 16,1 & 18,3 & 15,0 & 18,3 & 16,4 & 18,4 & 19,3 \\
\hline$>20$ mil e $<50$ mil & 47,4 & 32,9 & 25,7 & 29,3 & 30,4 & 27,8 & 30,7 & 32,5 & 32,0 & 31,1 & 29,1 & 25,5 & 29,2 & 28,1 & 29,1 & 25,9 & 28,2 & 24,0 & 23,4 & 26,8 & 23,1 & 25,7 & 22,7 & 24,4 \\
\hline$>50 \mathrm{mi}$ & 12,1 & 15,4 & 11,4 & 8,4 & 8,4 & 4,0 & 18,1 & 14,7 & 10,9 & 13,7 & 11,9 & 16,1 & 8,8 & 11,1 & 16,0 & 12,0 & 11,5 & 10,8 & 13,0 & 13,2 & 13,0 & 17,7 & 10,5 & 14,1 \\
\hline$>100$ mil e $<250$ mil & 10,5 & 11,4 & 5,7 & 6,0 & 7,2 & 5,5 & 8,0 & 7,0 & 9,1 & 7,7 & 6,3 & 11,5 & 12,4 & 8,0 & 12,5 & 10,7 & 8,0 & 13,2 & 9,3 & 10,5 & 10,9 & 7,3 & 12,1 & 8,9 \\
\hline e $<500$ mil & 22,3 & 8,0 & 5,0 & 1,6 & 0,4 & 0,1 & 4,6 & 3,8 & 2,9 & 2,4 & 2,7 & 3,1 & 2,0 & 2,6 & 1,9 & 3,4 & 2,6 & 4,1 & 3,1 & 5,0 & 3,1 & 4,8 & 3,1 & 4,6 \\
\hline$>500$ mil e $<1$ milhão & 0,6 & 2,8 & 0,4 & 4,5 & 4,6 & 1,9 & 2,4 & 2,4 & 2,7 & 1,2 & 1,6 & 1,4 & 2,2 & 1,7 & 3,2 & 6,8 & 2,4 & 7,0 & 5,6 & 5,4 & 6,6 & 5,0 & 5,5 & 8,1 \\
\hline Acima de 1 milhão & 4,5 & 4,6 & 3,4 & 2,1 & 3,5 & 6,1 & 2,3 & 2,8 & 4,0 & 2,1 & 5,2 & 1,2 & 3,6 & 2,4 & 4,4 & 9,1 & 10,2 & 8,3 & 9,7 & 7,1 & 10,9 & 9,3 & 11,4 & 6,5 \\
\hline
\end{tabular}

Fonte: MI. Elaboração própria. 
Tabela 4B - FNO, FNE e FCO: distribuição total dos valores contratados, segundo tamanho populacional dos municípios e por atividades majoritariamente urbanas (em \%)

\begin{tabular}{|c|c|c|c|c|c|c|c|c|c|c|c|c|c|c|c|c|c|c|c|c|c|c|c|c|}
\hline \multirow{2}{*}{ Porte do município } & \multicolumn{24}{|c|}{ Ano } \\
\hline & 1989 & 1990 & 1991 & 1992 & 1993 & 1994 & 1995 & 1996 & 1997 & 1998 & 1999 & 2000 & 2001 & 2002 & 2003 & 2004 & 2005 & 2006 & 2007 & 2008 & 2009 & 2010 & 201 & 2012 \\
\hline$<5$ mil & 0,0 & 0,0 & 0,4 & 0,1 & 0,8 & 0,8 & 0,4 & 0,5 & 0,9 & 0,4 & 1,0 & 0,1 & 0,2 & 0,5 & 0,7 & 0,4 & 1,2 & 0,2 & 0,7 & 1,6 & 0,4 & 0,9 & 0,5 & 0,5 \\
\hline$>5$ mil e $<$ & 0,0 & 0,6 & 12,2 & 1,1 & 7,6 & 0,0 & 2,6 & 1,0 & 3,3 & 2,4 & 1,2 & 0,5 & 1,5 & 8,0 & 0,6 & 2,4 & 2,0 & 0,9 & 1,6 & 2,3 & 0,9 & 3,6 & 2,6 & 2,2 \\
\hline$>10$ mil e & 0,0 & 0,0 & 21,4 & 27,2 & 19,5 & 21,2 & 6,2 & 4,4 & 9,4 & 4,5 & 3,0 & 6,2 & 5,0 & 9,4 & 3,0 & 8,6 & 13,0 & 2,7 & 7,1 & 7,4 & 12,5 & 13,3 & 13,9 & 12,6 \\
\hline$>20 \mathrm{r}$ & 0,0 & 7,3 & 18,6 & 29,7 & 37,9 & 57,2 & 14,7 & 21,8 & 15,5 & 10,8 & 15,6 & 13,0 & 10,6 & 24,5 & 9,1 & 17,7 & 22,4 & 10,9 & 11,3 & 20,0 & 18,1 & 17,9 & 17,9 & 15,5 \\
\hline e $<100$ mil & 0,0 & 11,8 & 15,4 & 4,2 & 7,2 & 7,2 & 16,8 & 14,6 & 10,8 & 27,2 & 21,8 & 7,3 & 8,7 & 13,9 & 21,9 & 10,5 & 10,8 & 8,3 & 14,6 & 16,6 & 14,8 & 23,3 & 11,1 & 19,0 \\
\hline$>100 \mathrm{~m}$ & 18,5 & 27,8 & 11,5 & 12,4 & 7,1 & 0,3 & 31,0 & 22,1 & 24,8 & 28,0 & 13,3 & 47,7 & 43,4 & 14,4 & 33,4 & 16,5 & 11,6 & 26,9 & 17,2 & 15,7 & 16,5 & 9,6 & 18,3 & 12,5 \\
\hline$>250$ & 71,7 & 19,6 & 9,1 & 5,5 & 3,7 & 1,2 & 7,6 & 7,6 & 4,3 & 4,7 & 4,9 & 10,3 & 5,2 & 11,2 & 4,4 & 4,6 & 4,5 & 9,0 & 5,4 & 9,2 & 4,5 & 6,8 & 5,0 & 8,3 \\
\hline$>500$ & 0,0 & 13,5 & 0,9 & 7,7 & 10,5 & 2,5 & 12,3 & 12,1 & 12,2 & 5,6 & 7,9 & 8,3 & 8,4 & 6,9 & 10,8 & 17,1 & 5,9 & 18,8 & 15,5 & 11,8 & 12,3 & 8,8 & 10,0 & 16,4 \\
\hline Acima de 1 milhão & 9,7 & 19,5 & 10,5 & 12,1 & 5,7 & 9,6 & 8,5 & 15,8 & 18,6 & 16,4 & 31,3 & 6,6 & 17,0 & 11,2 & 16,1 & 22,2 & 28,6 & 22,3 & 26,5 & 15,5 & 20,0 & 15,8 & 20,6 & 12,9 \\
\hline
\end{tabular}

Fonte: MI. Elaboração própria.

Tabela 4C - FNO, FNE e FCO: Distribuição total dos valores contratados, segundo tamanho populacional dos municípios e por atividades majoritariamente rurais (em \%)

\begin{tabular}{|c|c|c|c|c|c|c|c|c|c|c|c|c|c|c|c|c|c|c|c|c|c|c|c|c|}
\hline \multirow[b]{2}{*}{ Porte do município } & \multicolumn{24}{|c|}{ Ano } \\
\hline & 1989 & 1990 & 1991 & 1992 & 1993 & 1994 & 1995 & 1996 & 1997 & 1998 & 1999 & 2000 & 2001 & 2002 & 2003 & 2004 & 200 & 2006 & 2007 & 2008 & 2009 & 201 & 201 & 201 \\
\hline$<5$ mil & 0,0 & 4,0 & 2,4 & 4,3 & 6,2 & 7,5 & 4,8 & 4,3 & 6,7 & 5,1 & 7,0 & 6,6 & 9,6 & 12,3 & 8,4 & 10,0 & 11,5 & 10,8 & 12,1 & 12,7 & 12,9 & 11,5 & 10,0 & 10,5 \\
\hline$>5$ mil e $<10$ mil & 0,0 & 8,6 & 9,1 & 16,7 & 15,2 & 9,4 & 11,0 & 11,4 & 9,8 & 13,3 & 15,2 & 18,0 & 16,3 & 13,2 & 11,9 & 14,6 & 13,0 & 14,4 & 13,7 & 15,2 & 15,9 & 13,9 & 21,7 & 14,4 \\
\hline$>10$ mil e $<20$ mil & 3,8 & 15,6 & 40,5 & 30,0 & 25,7 & 40,1 & 22,6 & 26,9 & 27,4 & 27,5 & 27,5 & 22,5 & 24,1 & 26,1 & 22,4 & 20,2 & 23,7 & 23,7 & 24,5 & 21,1 & 25,0 & 20,4 & 23,6 & 25,7 \\
\hline$>20$ mil e $<50$ mil & 68,7 & 36,5 & 27,5 & 29,3 & 29,7 & 25,7 & 33,7 & 34,5 & 35,7 & 33,4 & 31,5 & 27,8 & 33,7 & 28,8 & 35,8 & 31,0 & 31,2 & 31,5 & 30,1 & 32,2 & 28,8 & 35,6 & 28,5 & 32,8 \\
\hline$>50$ mil e $<100$ mil & 17,5 & 15,9 & 10,4 & 9,0 & 8,5 & 3,8 & 18,4 & 14,8 & 11,0 & 12,1 & 10,2 & 17,6 & 8,8 & 10,6 & 14,0 & 13,0 & 12,0 & 12,3 & 12,2 & 10,4 & 10,9 & 10,6 & 9,7 & 9,3 \\
\hline$>100$ mil e $<250 \mathrm{mil}$ & 6,8 & 9,1 & 4,2 & 5,0 & 7,2 & 5,9 & 3,8 & 4,2 & 5,6 & 5,4 & 5,1 & 5,2 & 5,1 & 6,7 & 5,5 & 7,2 & 6,0 & 5,4 & 4,9 & 6,2 & 4,5 & 4,4 & 4,7 & 5,5 \\
\hline$>250 \mathrm{mil} \mathrm{e}<500 \mathrm{mil}$ & 0,0 & 6,3 & 3,9 & 1,0 & 0,1 & 0,0 & 4,1 & 3,1 & 2,6 & 2,2 & 2,3 & 1,8 & 1,3 & 0,9 & 1,1 & 2,7 & 1,6 & 1,3 & 1,9 & 1,6 & 1,4 & 2,3 & 0,9 & 1,2 \\
\hline$>500$ mil e $<1$ milhão & 0,9 & 1,3 & 0,3 & 4,1 & 4,1 & 1,9 & 0,5 & 0,5 & 0,6 & 0,6 & 0,5 & 0,1 & 0,8 & 0,7 & 0,7 & 0,5 & 0,5 & 0,2 & 0,2 & 0,2 & 0,1 & 0,3 & 0,2 & 0,3 \\
\hline Acima de 1 milhão & 2,2 & 2,5 & 1,7 & 0,7 & 3,3 & 5,8 & 1,1 & 0,3 & 0,7 & 0,4 & 0,7 & 0,3 & 0,4 & 0,7 & 0,4 & 1,0 & 0,5 & 0,4 & 0,4 & 0,3 & 0,4 & 1,0 & 0,7 & 0,4 \\
\hline
\end{tabular}

Fonte: MI. Elaboração própria. 


\section{Considerações finais}

Qualquer política de desenvolvimento regional deve levar em conta as características e os aspectos do Brasil que foram moldados ao longo de sua secular história econômica e que deixaram marcas duradouras em sua organização socioespacial, cuja evidência mais destacada é a dos "desequilíbrios regionais". Ser um país de passado colonial, periférico, subdesenvolvido, dependente, federativo, continental, populoso, com grande diversidade ecológica e cultural, mas também com fortes desigualdades econômicas e socioespaciais, impõe imensos desafios para resolver a problemática regional.

Aqui foi abordado um desses desafios: o financiamento da política regional brasileira pelos Fundos Constitucionais de Financiamento. Observou-se que mesmo após a PNDR estabelecer prioridades, o FNO e o FCO - que abarcam áreas de fronteira do crescimento brasileiro (a extrativa mineral e a agricultura tecnificada) - aumentaram a destinação de recursos para microrregiões de Alta Renda, enquanto no Nordeste observou-se decréscimo para elas, o que demonstra a dificuldade para se atingir os objetivos propostos.

Já foi apresentado por vários autores que a própria lógica do FNO, FNE e FCO se pauta por critérios de mercado. Basta mencionar que na condição de principal fonte de financiamento da PNDR, eles não apresentam linhas de financiamentos não reembolsáveis que possam atender outras necessidades, como por exemplo, a montagem de infraestruturas públicas consorciadas com prefeituras para $\mathrm{o}$ desenvolvimento de regiões que precisam delas para promover o avanço de suas atividades econômicas. Há áreas para as quais o financiamento dos Fundos não chegará a contento, posto tratar-se de crédito reembolsável, ainda que com taxas de juros potencialmente mais baixas. Portanto, seria preciso pensar em linhas não reembolsáveis, ainda que para isso deva ser feito o difícil enfrentamento das elites territoriais que se encastelam nos orçamentos e fundos públicos, se apropriando deles.

Da mesma forma, determinadas atividades dinâmicas poderiam obter crédito em outras fontes, como as disponíveis pelo BNDES. Regionalmente, é um paradoxo que a PNDR amplie o escopo da questão regional brasileira para todo o território a partir de critérios pré-definidos, porém, constitucionalmente, os recursos sejam destinados exclusivamente para as regiões Norte, Nordeste e Centro-Oeste. Esta última fora incorporada na Carta de 1988, o que possibilitou a combinação de fundos públicos e fundos territoriais no avanço do agronegócio de exportação da região, numa clara indicação de que interesses setoriais podem ser maiores do que os regionais.

A ausência de um FNDR e as dificuldades para constituí-lo, dado os conflitos federativos que o envolvem, dão a exata dimensão dos desafios, ao mesmo tempo 
em que expõem os limites dos Fundos Constitucionais de Financiamento como instrumento para levar a bom termo as transformações requeridas para superação socialmente justa do problema regional brasileiro.

\section{Referências}

ANGELIS, A. Substituição tributária no ICMS - problemas e possíveis soluções. Monografia apresentada à Federação Nacional dos Fiscos Estaduais FENAFISCO - mimeo. São Paulo, 2012, 93 p.

BRAGA, V. Logística e uso do território brasileiro: tipologia e topologia de nós logísticos e projeto da Plataforma Multimodal de Goiás (PLMG). 2013. 209 fls. Tese (Doutorado em Geografia) - Instituto de Geociências, Universidade Estadual de Campinas, Campinas.

CANO, W. Raízes da concentração industrial em São Paulo. 3. ed. São Paulo: HUCITEC, 1990, 391 p.

. Desequilíbrios regionais e concentração industrial no Brasil: 19301970, Campinas: IE-UNICAMP, 1998, 421 p.

. Celso Furtado e a questão regional no Brasil. In: TAVARES, M. C. (Org.). Celso Furtado e o Brasil. São Paulo: Perseu Abramo, 2001, p. 93-120.

. Descontração produtiva regional do Brasil 1970-2005. São Paulo: UNESP, 2008, 294 p.

A desindustrialização no Brasil. Campinas: IE/UNICAMP, 2012 (Textos para Discussão, n ${ }^{\circ}$ 200).

CARDOZO, S. A. Guerra Fiscal no Brasil e alterações nas estruturas produtivas estaduais nos anos 1990. 2010. 315 fls. Tese (Doutorado em Desenvolvimento Econômico) - Instituto de Economia, Universidade Estadual de Campinas, Campinas.

CARNEIRO, R. Impasses do desenvolvimento brasileiro: a questão produtiva. Texto para discussão, Campinas, $\mathrm{n}^{\mathrm{o}}$ 153, nov. 2008, 55 p. Disponível em: $<$ http://www.eco.unicamp.br/docdownload/publicacoes/textosdiscussao/texto 153.pdf $>$. 
CASTILHO, A. L. Partido da Terra - como os políticos conquistam o território brasileiro. São Paulo: Contexto, 2012, 239 p.

CINTRA, M. A. M. Fundos Constitucionais de Financiamento (do Norte, Nordeste e Centro-Oeste). Campinas: IE-UNICAMP/MTE/DIEESE. Projeto de Pesquisa "O Brasil na era da Globalização: condicionantes domésticos e internacionais ao Desenvolvimento" (Subprojeto IX: Crédito direcionado e desenvolvimento econômico no Brasil: o papel dos fundos públicos), Relatório 3, $\mathrm{s} / \mathrm{d}, 95 \mathrm{p}$.

DELGADO, G. Do capital financeiro na agricultura à economia do agronegócio - mudanças cíclicas em meio século (1965-2012). Porto Alegre: Editora da UFGRS, 2012, 144p.

DINIZ, C. C. (Org.). Políticas de desenvolvimento regional - desafios e perspectivas à luz das experiências da União Europeia e do Brasil. Brasília: Editora da UNB, 2007.

FURTADO, C. Formação Econômica do Brasil. São Paulo: Editora nacional, 1980, $248 \mathrm{p}$.

HARVEY, D. Espaços de Esperança. São Paulo: Edições Loyola, 2004, 382 p.

. A produção capitalista do espaço. São Paulo: Annablume, 2005, 251p.

2008, 248p.

Neoliberalismo - história e implicações. São Paulo: Edições Loyola,

LEAL, V. N. Coronelismo, Enxada e Voto - o município e o regime representativo no Brasil. Rio de Janeiro: Edição Revista Forense, 1948, 311 p.

MACEDO, F. C. Inserção externa e território: impactos do comércio exterior na dinâmica regional e urbana do Brasil (1989-2008). 2010. 302 fls. Tese (LivreDocência). IE-UNICAMP, Campinas, 2010a.

Inserção comercial externa e dinâmica territorial no Brasil. Redes, Santa Cruz do Sul, v. 15, p. 89-114, 2010 b.

- Transformação econômica, inserção externa e dinâmica territorial no Centro-Oeste brasileiro: o caso de Rio Verde. Sociedade \& Natureza (UFU. Online), v. 25, n.1, p. 35-50, 2013. 
MACEDO, F. C. ANGELIS, A. Guerra fiscal dos portos e desenvolvimento regional no Brasil. Redes, Santa Cruz do Sul, v. 18, p. 185-212, 2013.

MACEDO, F. C.; MATOS, E. N. Avaliação do FNE no desenvolvimento regional baiano no período pós-real. Bahia Análise \& Dados, v. 16, p. 621-633, 2007.

O papel dos Fundos Constitucionais de Financiamento no desenvolvimento regional brasileiro. Ensaios FEE (Impresso), v. 29, p. 355-384, 2008.

MARINI, R. M [1973]. Dialética da Dependência. In: TRASPADINI, R.; STEDILE, J. P. (Org.). Ruy Mauro Marini - vida e obra. São Paulo: Expressão Popular, 2005, p. 137-180.

MINISTÉRIO DA INTEGRAÇÃO. Fundos Constitucionais de Financiamento - 20 anos (desempenho operacional). Brasília: SDR/MI, 2009. Disponível em: <http://www.integracao.gov.br/c/document_library/get_file? uuid=beabe174-cd93-4b2c-9857-05b73b31ab8d\&groupId=407753 >. Acesso em: 20 mai. 2013.

MORAES, A. C. R. Território e História no Brasil. São Paulo: Annablume/Hucitec, 2002, 154 p.

MOREIRA, R. Repensando a Geografia. In: SANTOS, M. (Org.). Novos rumos da geografia brasileira. 4. ed. São Paulo: HUCITEC, 1996, p. 35-49.

MUELLER, C. C. Políticas governamentais e a expansão recente da agropecuária no Centro-Oeste. Planejamento e Políticas Públicas, v. 3, n. 1, p. 45-74, 1990.

OLIVEIRA, F. Elegia para uma re(li)gião. 5. ed. São Paulo: Editora Paz e Terra, 1987. 137 p.

A metamorfose do arribação - fundo público e regulação autoritária na expansão do Nordeste. In: OLIVEIRA, F. Os direitos do anti-valor - a economia política da hegemonia imperfeita. Petrópolis: Vozes, 1998, p. 79-120.

PEREIRA, P. G. Dificuldades na implementação da Política Nacional de Desenvolvimento Regional (PNDR): impasses, embates e conflitos - uma contribuição ao debate. 2009. 220f. Dissertação (Mestrado em Planejamento Urbano e regional) - Instituto de Pesquisa e Planejamento Urbano e Regional, UFRJ, Rio de Janeiro, 2009. 
PRADO, S. A. "Federação inconclusa": o papel dos governos estaduais na Federação brasileira. In: REZENDE, F. (Org.). O federalismo brasileiro em seu labirinto: crise e necessidade de reformas. São Paulo, Editora da FGV, 2013, p. $120-197$.

PRADO, S., CAVALCANTI, C. E. G. A guerra fiscal no Brasil. São Paulo: Fundap/FAPESP; Brasília: IPEA, 2000, 146 p.

REZENDE, F. A crise do federalismo brasileiro: evidências, causas e consequências. In: REZENDE, F. A. (Org.). $\mathbf{O}$ federalismo brasileiro em seu labirinto: crise e necessidade de reformas. São Paulo, Editora da FGV, 2013, p. 14-65.

ROFMAN, A. Desigualdades regionales y concentración económica: el caso Argentino. Buenos Aires: Ediciones Siap, 1974, 150 p.

SAMPAIO, D. P. A desindustrialização em marcha no Brasil. Revista da Sociedade Brasileira de Economia Política, v. 34, p. 33-55, 2013.

SECRETARIA DE DESENVOLVIMENTO REGIONAL. I Conferência Nacional de Desenvolvimento Regional - Documento de Referência. Brasília: SDR/MI, 2012, 77 p. Disponível em <http://www.integracao.gov.br/c/ document_library/get_file?uuid=54bce099-503a-4076-8613-d90dd6107c79\&gro upId=10157>. Acesso em: 14 abr. 2014.

SVAMPA, M., Consenso de los Commodities y lenguajes de valoración en América Latina. Argentina, Revista Nueva Sociedad, n. 244, marzo-abril de 2013.

VARGAS, D. B. Planejamento regional no Brasil no século XXI: a Política Nacional de Desenvolvimento Regional. 2013. 94 fls. Dissertação (Mestrado em Desenvolvimento Regional) - Centro de Ciências Humanas e da Comunicação. Universidade Regional de Blumenau, Blumenau.

VIEIRA, D. J. Um estudo sobre a Guerra Fiscal no Brasil. 2012. 218 fls. Tese (Doutorado em Desenvolvimento Econômico) - Instituto de Economia. Universidade Estadual de Campinas, Campinas.

Endereço para correspondência:

Fernando Cezar de Macedo - fernando.cezar.macedo@gmail.com

Cidade Universitária Zeferino Vaz, Barão Geraldo

13083-970 Campinas/SP, Brasil 